\title{
Estradiol Increases Microglial Response to Lipopolysaccharide in the Ventromedial Hypothalamus during the Peripubertal Sensitive Period in Female Mice
}

\author{
Amarylis Velez-Perez, ${ }^{2,3}$ Mary K. Holder, ${ }^{1,2,3}$ Sam Fountain, ${ }^{1}$ and ${ }^{\circledR}$ Jeffrey D. Blaustein ${ }^{1,2,3}$
}

https://doi.org/10.1523/ENEURO.0505-19.2020

${ }^{1}$ Department of Psychological and Brain Sciences, University of Massachusetts, Amherst, MA 01003, ${ }^{2}$ Neuroscience and Behavior Program, University of Massachusetts, Amherst, MA 01003, and ${ }^{3}$ Center for Neuroendocrine Studies, University of Massachusetts, Amherst, MA 01003

\begin{abstract}
Sensitive periods are times of development during which the effects of experience are unusually strong and long lasting. The peripubertal period has emerged as one such sensitive period, and a single administration of lipopolysaccharide (LPS) during this time reduces hormone-induced sexual behavior in adult female mice. During periods of high synaptic turnover, maturation, and elimination, as occurs during this sensitive period, microglia are particularly active. Estradiol also regulates microglial numbers, morphology, and activation. In addition, a good deal of evidence suggests that estradiol may confer this vulnerability to the effects of a stressor during the peripubertal period. Therefore, we investigated the effects of estradiol on microglial morphology, cytokine levels, and the sickness response to LPS. Estradiol levels were manipulated by implanting an estradiolfilled SILASTIC capsule (or oil-filled control) in ovariectomized mice or by administering the aromatase inhibitor, formestane (or oil control), to ovary-intact mice. We found that (1) estradiol elevates basal microglial Iba1 immunoreactivity in the ventromedial nucleus of the hypothalamus (VMH), (2) LPS induces higher levels of proinflammatory cytokines in the presence of estradiol, and (3) LPS causes hypothermia in the presence of estradiol. Taken together, these data suggest that estradiol enhances the effect of LPS during the pubertal sensitive period.
\end{abstract}

Key words: estradiol; Iba1; mice; microglia; peripubertal development

\section{Significance Statement}

The experience of trauma or extreme stressors, including immunostressors, during the peripubertal period can lead to marked and pervasive alterations of behavior. The underlying mechanisms contributing to this vulnerability during the peripubertal period are not understood. Microglia have emerged as a candidate through which stress might impact neurodevelopment and subsequently behaviors. Few studies have investigated how the developmental changes in levels of estrogens during the peripubertal period influence the microglia. Here, we find that exposure to estradiol during the peripubertal period enhances the microglial response to an immune challenge. These findings suggest a mechanism through which estradiol may confer vulnerability to an immunostressor during the sensitive, peripubertal period.

Received November 27, 2019; accepted June 9, 2020; First published June 18, 2020.

The authors declare no competing financial interests.
Author contributions: A.V.-P. and J.D.B. designed research; A.V.-P. and S.F. performed research; A.V.-P. and M.K.H. analyzed data; A.V.-P., M.K.H., and J.D.B. wrote the paper. 


\section{Introduction}

Sensitive periods are developmental windows during which the effects of experience can lead to enduring effects (Knudsen, 2004). Stressful experiences can perturb normal development processes to reorganize brain circuits regulating behavior (Avital and Richter-Levin, 2005; Blaustein and Ismail, 2013; Green and McCormick, 2013). One such sensitive period is pubertal development as indicated by a comprehensive series of experiments on the age vulnerability on the behavioral sequelae (Laroche et al., 2009b). In particular, an immune challenge like the bacterial endotoxin, lipopolysaccharide (LPS), or stress from shipping during pubertal development, but not other times, decreases subsequent hormone-induced female sexual behavior in adult female mice (Ismail et al., 2011; Olesen et al., 2011; Laroche et al., 2009a,b). While males shipped at six weeks also show reduced mounts in a sexual behavior test, this effect is less robust than in females (Laroche et al., 2009b); therefore, we have chosen to focus on effects of peripubertal LPS in females.

During sensitive periods of development, there are marked changes in the architecture of brain regions via cell genesis, cell death, and synaptic remodeling (Tremblay et al., 2010; Schafer et al., 2012). Moreover, microglia, the resident-immune cells of the brain, are particularly active during these processes (Paolicelli and Gross, 2011), suggesting that the role of microglia in monitoring the brain microenvironment is particularly important during sensitive periods of development. For example, the complement system, part of the innate immune system, instructs microglia to engulf and eliminate immature synapses (Stevens et al., 2007). Disruption of key signaling molecules in this pathway alters the establishment of neural circuits (Hong and Stevens, 2016). One of the signaling molecules secreted by microglia that is crucial for normal developmental processes are cytokines (Bilbo and Schwarz, 2009). Therefore, it is likely that an inflammatory insult like an LPS injection can alter the cytokine signaling, permanently remodeling neural circuits (Bilbo and Schwarz, 2012). In fact, a bacterial infection or LPS administration to neonatal male rats increases brain cytokines levels, inducing long-term changes in microglial activation and behavior (Bilbo et al., 2005, 2008). Juvenile and adult female rats, however, have a more activated phenotype of microglia, compared with males (Schwarz et al., 2012). Thus, microglia may mediate the enduring effects of LPS in pubertal female mice, and indeed, a single injection of LPS causes

This work was supported by the National Science Foundation Grant IOS 1050179 (to J.D.B.)

M. K. Holder's present address: School of Psychology, Georgia Institute of Technology, Atlanta, GA 30332

Acknowledgements: We thank Jillian Gallagher, Amanda Robare, David Placzek, Sreeja Bapatla, and Julia O'Connell for technical assistance. We also thank the Mouse Metabolic and Phenotyping Center at the University of Massachusetts Medical School for cytokine level analyses.

Correspondence should be addressed to Mary K. Holder at mary.holder@ psych.gatech.edu.

https://doi.org/10.1523/ENEURO.0505-19.2020

Copyright $@ 2020$ Velez-Perez et al.

This is an open-access article distributed under the terms of the Creative Commons Attribution 4.0 International license, which permits unrestricted use, distribution and reproduction in any medium provided that the original work is properly attributed. a stronger microglial activation in peripubertal mice compared with adult mice receiving the same LPS treatment (Holder and Blaustein, 2017). Overall, these data suggest that microglia are particularly active during sensitive periods of development, and further activation by an immune challenge may have implications for the establishment of neuronal circuits regulating behavior.

One of the hallmarks of the peripubertal period is the maturation of the reproductive axis, resulting in the secretion of gonadal steroid hormones. As these gonadal hormones impact neurobiological processes regulating reproduction at the molecular, cellular, physiological, and behavioral levels, it is likely that estradiol may shape these neuronal circuits during pubertal development. For example, full expression of female sexual receptivity in adulthood depends on peripubertal secretion of estradiol (Bakker et al., 2003). Aromatase knockout females display low levels of hormone-induced sexual behavior in adulthood (Bakker et al., 2003), and exposure to peripubertal, but not prepubertal (post-natal day; P5-P15), estradiol rescues adult sexual behavior (Brock et al., 2011). This suggests that the timing and exposure of the brain to gonadal hormones are critical factors driving the full maturation of the reproductive behavioral repertoire.

One way in which estradiol can shape neuronal circuits is by regulating microglia. Microglia express estrogen receptors (ER; Sierra et al., 2008), suggesting that estrogens can modulate the onset, duration, and/or culmination of neuroinflammation. In addition, estradiol can regulate microglial numbers, morphology and cytokine expression at basal levels (Mor et al., 1999) and after an immune challenge (Vegeto et al., 2001). Therefore, we hypothesized that estradiol confers vulnerability to LPS by enhancing the immune response during the peripubertal development in female mice. To test this hypothesis, we manipulated estradiol levels by administering an estradiol capsule to ovariectomized mice or by administering the aromatase inhibitor formestane (or oil to the control group). We quantified changes in the morphometric properties of microglia in the ventromedial nucleus of the hypothalamus (VMH), we examined the effects of LPS on interleukin (IL)- $1 \alpha$, IL-1 $\beta$, IL-6, IL-10, and tumor necrosis factor (TNF)- $\alpha$ protein levels, and we quantified changes in behavior (lethargy), physiology (thermoregulation), and metabolism (body weight), all of which are critical components of sickness behavior and constitute an organized response to immune activation (Dantzer, 2001).

\section{Materials and Methods}

\section{Animals}

Female C57BI/6 mice were shipped from Charles River Laboratories on P21 and housed in an all-female colony room. The room was under controlled temperature $\left(24 \pm 2^{\circ} \mathrm{C}\right)$ and reversed $14 / 10 \mathrm{~h}$ light/dark cycle (zeitgeber time was 8 P.M., with lights off at 10 A.M.). Mice were housed in groups of four in clear polycarbonate cages with ad libitum access to food (Teklad 2014, phytoestrogen-reduced diet, Harlan Laboratories) and water in glass bottles. All procedures were performed according to the 
National Institutes of Health Guide for the Care and Use of Laboratory Animals and in accordance with the University of Massachusetts, Amherst Institutional Animal Care and Use Committee' regulation. Experimenters were blinded to all experimental treatments.

\section{Ovariectomy and capsule implantation}

On P28, mice were anesthetized with isoflurane $(3 \%$, inhaled), and a single incision was made to the dorsal skin and the muscle layer to locate the uterine horns. The uterine horns were clamped, the ovaries were removed, and the tips of the uterine horns were cauterized with an AcuCautery (Acuderm Inc). The muscle layer was sutured with an absorbable suture (Ethicon), and the incision was closed using surgical wound clips (Becton Dickinson). For capsule implantation, a small incision was made to the skin layer of the neck, and a 2.5-cm-long SILASTIC capsule $(1.57 \mathrm{~mm}$ inner diameter $\times 3.18 \mathrm{~mm}$ outer diameter; Dow Corning) filled with estradiol or sesame oil was implanted (Knox et al., 2009). The incision was closed using surgical wound clips. Mice were transferred to a heating pad to recover until they were fully awake, and they were returned to their home cage.

\section{E-mitter implant}

During the ovariectomy procedure, mice received a G2 E-mitter device (E-mitter Respironics Mini-mitter) to record core body temperature and activity levels. The E-mitter was sutured to the abdominal muscle wall to keep its placement stable. Before implantation, the E-mitter was washed with Tergazyme, a detergent with protease enzyme activity. Following Tergazyme, E-mitters were incubated in 3\% glutaraldehyde to disinfect and sterilize the E-mitter and rinsed with sterile saline at least three times. Radio signals for locomotion and temperature were recorded by a receiver board (ER-4000 energizer receiver) underneath the cage housing each animal and stored via Vital View Data Acquisition System (version 4.1; Mini Mitter) in the laboratory computer. Mice were allowed to recover from E-mitter implant surgery for at least one week before onset of the experiments. Data were collected in 2-min bins, starting $24 \mathrm{~h}$ before the injection until decapitation (at either 6 or $24 \mathrm{~h}$ following LPS or vehicle injection).

\section{Estradiol administration}

United States Pharmacopeia (USP) grade $17 \beta$-estradiol $E_{2}$ was obtained from Sigma-Aldrich. Estradiol was dissolved in sesame oil (vehicle) to a concentration of $50 \mu \mathrm{g} /$ $25 \mu \mathrm{l}$. Mice were randomly assigned to treatment groups and received a SILASTIC capsule (Dow Corning) filled with estradiol (50 $\mu \mathrm{g} \mathrm{E}_{2} / 25 \mu \mathrm{l}$ sesame oil) or sesame oil.

\section{Aromatase inhibitor formestane}

Biosynthesis of estrogens is catalyzed by the rate-limiting, cytochrome P450 enzyme, aromatase (Yue and Brodie, 1997). This can be inhibited by aromatase inhibitors like formestane (4-hydroxyandrostendione), which acts as a steroidal substrate analog (Yue and Brodie,
1997; Simpson and Dowsett, 2002). Mice were subcutaneously injected with formestane or sesame oil for seven consecutive days, starting on P35 through P42 at a dose of $20 \mu \mathrm{g} / \mathrm{kg}$. This dose of formestane decreases neural estradiol levels in vivo in neonatal rats (Amateau et al., 2004). In addition, this dose and injection schedule reduces estradiol-dependent changes in dendritic spine morphology in P7-P13 perinatal rats (Dean et al., 2012).

\section{LPS treatment}

LPS from Escherichia coli serotype 026:B6 was obtained from Sigma-Aldrich. The LPS was dissolved in sterile saline (vehicle) to a concentration of $0.1 \mathrm{mg} / \mathrm{ml}$. Mice were randomly assigned to treatment groups and received a single intraperitoneal injection of LPS $(1.5 \mathrm{mg} / \mathrm{kg}$ body weight) or an equivalent volume of sterile saline on P42. Injections were administered within $1 \mathrm{~h}$ before the onset of the dark phase of the light/dark cycle. Animals were returned to their home cage immediately following injection. Mice were weighed immediately before injection, as well as 6 and $24 \mathrm{~h}$ following treatment to assess the effect of LPS on body weight.

\section{Tissue collection}

Mice were deeply anesthetized with an intraperitoneal injection of pentobarbital $(100 \mathrm{mg} / \mathrm{kg})$ and decapitated. Brains were removed from the skull and fixed in $4 \%$ paraformaldehyde in PBS $(0.05 \mathrm{M}, \mathrm{pH} 7.4)$ at $4^{\circ} \mathrm{C}$ for $24 \mathrm{~h}$, followed by incubation in 30\% sucrose in $0.1 \mathrm{~m}$ PBS for at least $72 \mathrm{~h}$. Brains were sectioned coronally in $30-\mu \mathrm{m}$-thick sections using a cryostat. Brain sections were stored in cryoprotectant at $-20^{\circ} \mathrm{C}$ until they were immunostained.

\section{Iba1 immunocytochemistry}

Free-floating brain sections were rinsed for $3 \times 5 \mathrm{~min}$ in $0.05 \mathrm{~m}$ tris-buffered saline (TBS) and also rinsed before each subsequent step, except between the blocking and primary antibody steps. Brain sections were incubated in a blocking buffer containing $20 \%$ normal goat serum, $3.5 \%$ hydrogen peroxide, and $1 \%$ bovine serum albumin in gel TBS for $1 \mathrm{~h}$. Brain slices were incubated for $48 \mathrm{~h}$ at $4^{\circ} \mathrm{C}$ in a solution containing Iba1 primary antibody (Wako catalog \#019-19741, RRID:AB_839504) at a 1:10,000 dilution. The primary lba1 antibody was diluted in $2 \%$ normal goat serum and $0.5 \%$ Triton X-100 in gel TBS. After $48 \mathrm{~h}$, sections were incubated for $90 \mathrm{~min}$ at room temperature in a solution of biotinylated secondary antibody in gel TBS. The avidin-biotin complex (ABC) was used to bind a complex of streptavidin-biotin peroxidase to the secondary antibody for $90 \mathrm{~min}$. The reaction was then developed with diaminobenzidine (DAB; Vector Laboratories) for $20 \mathrm{~min}$ to produce a colorimetric stain. Brain sections were rinsed in TBS and mounted on gelatin-coated slides, dehydrated, and coverslipped with Polymount.

\section{Microscopic analysis of Iba1}

Three bilateral photomicrographs of carefully matched sections of $\mathrm{VMH}$ were taken from each animal using a Nikon Optiphot-2 microscope connected to a Qlmaging 
Table 1: Experiment 1 statistical analysis

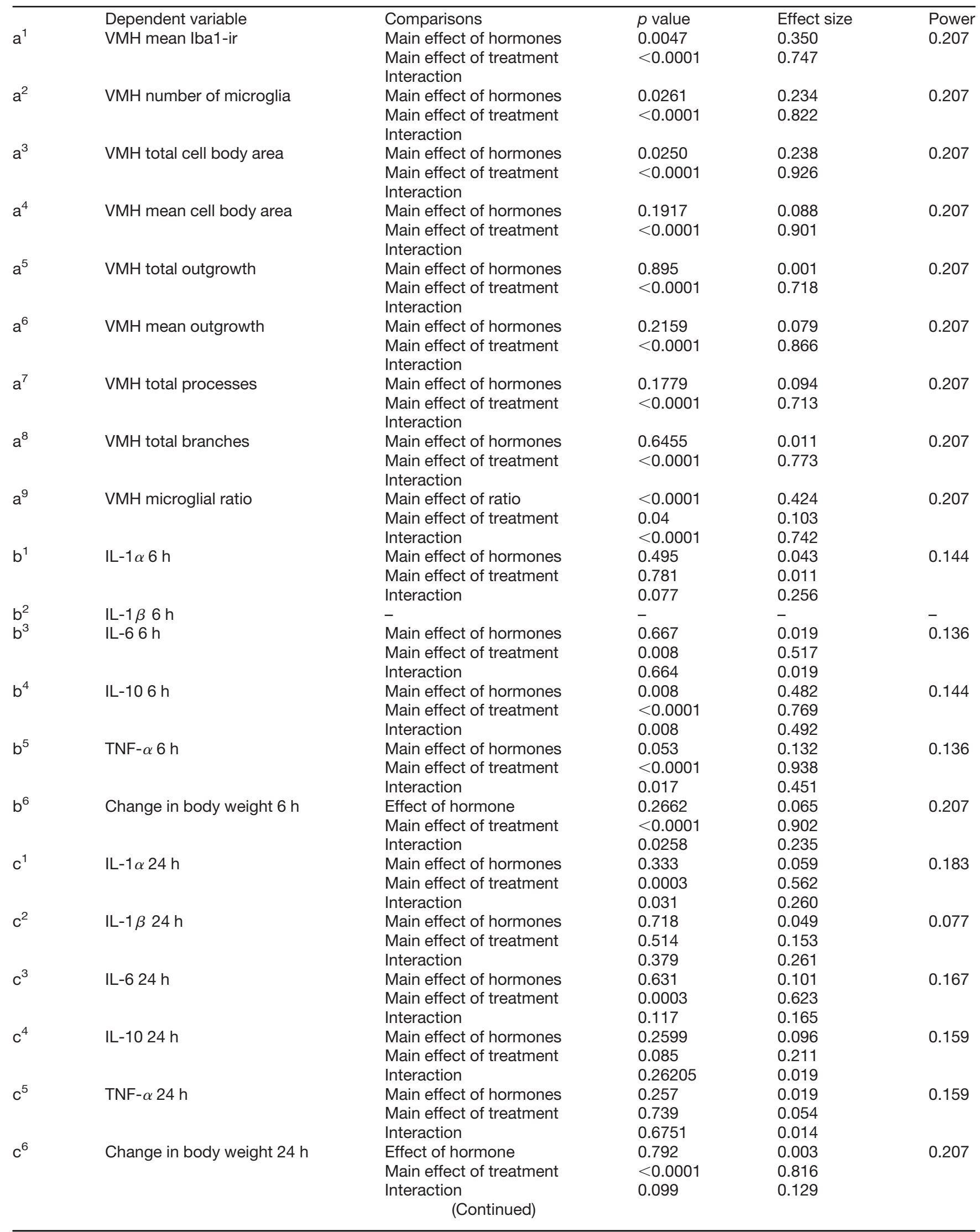


Table 1: Continued

\begin{tabular}{|c|c|c|c|c|c|}
\hline & Dependent variable & Comparisons & $p$ value & Effect size & Power \\
\hline$d^{1}$ & Estradiol & Main effect of hormone & $<0.0001$ & 0.840 & 0.269 \\
\hline \multirow[t]{3}{*}{$e^{1}$} & Change in temperature & Main effect of time & $<0.0001$ & 0.335 & 0.128 \\
\hline & & Main effect of treatment & 0.005 & 0.204 & \\
\hline & & Interaction & $<0.0001$ & 0.127 & \\
\hline \multirow[t]{3}{*}{$e^{2}$} & Change in locomotion & Main effect of time & $<0.0001$ & 0.298 & 0.128 \\
\hline & & Main effect of treatment & $<0.0001$ & 0.224 & \\
\hline & & Interaction & $<0.0001$ & 0.281 & \\
\hline
\end{tabular}

Experiment 1. The effect of estradiol on microglial, cytokine, and physiological response to LPS.

Micropublisher RTV 5.0 camera. The identification of this area was based on plate 43-44 of the Mouse Brain Atlas in Stereotaxic Coordinates, using the shape of the third ventricle as a landmark (Franklin and Paxinos, 1997). Gray-scale images of the VMH were obtained using the ImageJ software (NIH Image, Scion Image), and Iba1 staining was measured using a maximum entropy thresholding algorithm approach, a widely used broad approach to measure Iba1 immunoreactivity (Beynon and Walker, 2012). Detailed morphometric analysis of individual microglia was obtained using the MetaMorph Neurite Outgrowth program (Molecular Devices; version 7.7). We measured changes in microglia morphology by quantifying the number of microglia, total cell body size, mean cell body area, total outgrowth, mean outgrowth, total branches, and total processes. While the quantification of global changes in Iba1 immunoreactivity is common, it can lead to the incorrect assumption that microglia have the same function or that their effects are additive, because the data are reported as an average profile (Beynon and Walker, 2012; Gertig and Hanisch, 2014). In order to capture microglial heterogeneity and morphologic changes after LPS within the $\mathrm{VMH}$, we performed a ratio analysis that involved quantifying microglial cell body size over microglial ramifications (Hovens et al., 2015). A ratio between 0.00 and 0.99 reflects properties of highly ramified microglia (basal and/or surveying microglia), whereas a ratio of 3.00 and above reflects activated microglia (large somata and short or nearly non-existent processes, associated with a phagocytic stage). Microglia with stout processes (intermediate ratio 1.0-2.99) can function as dendritic cells (Hanisch, 2013). As mice were not perfused before collecting the brains, it is possible that the Iba1 staining may reflect microglia but also monocytes and macrophages near the blood vessels. Brain regions were identified using the Mouse Brain Atlas in Stereotaxic Coordinates, plates 43-44 (Franklin and Paxinos, 1997).

\section{Plasma}

Mice were deeply anesthetized with an intraperitoneal injection of pentobarbital $(100 \mathrm{mg} / \mathrm{kg})$ and decapitated. Trunk blood was collected into an EDTA-treated tube (BD Vacutainer) and placed on ice. Blood was centrifuged at $4^{\circ} \mathrm{C}$ in a microcentrifuge (Eppendorf). Following centrifugation, plasma was aliquoted and stored at $-80^{\circ} \mathrm{C}$ until assayed. Estradiol levels were determined using the mouse estradiol ELISA kit (Calbiotech). The level of detection is $3 \mathrm{pg} / \mathrm{ml}$, which is consistent with the results of McNamara et al. (2010), in which the levels of estradiol were found to be $<5 \mathrm{pg} /$ $\mathrm{ml}$ in adult female mice.

\section{Cytokine protein quantification}

Cytokine protein levels in plasma were measured 6 and $24 \mathrm{~h}$ after LPS administration. The 6-h time point was selected because, in a time course profile of cytokine levels $6 \mathrm{~h}$ post-LPS, this was the optimal time point to measure the peak levels of cytokines of interest. It is also the time point at which a single peripheral LPS injection causes significant breakdown of the blood brain barrier (Brown et al., 2010). The 24-h time point was selected to determine how cytokine levels at this time point relate to microglial changes. The levels of IL-1 $\alpha$, IL-1 $\beta$, IL-6, IL-10, and TNF- $\alpha$ were analyzed using the Luminex Multiplex Instrument Bio-Plex 200 system from samples shipped to the Mouse Metabolic and Phenotyping Center at the University of Massachusetts Medical School.

\section{Statistics}

Data are represented as means \pm SEM. We examined the effect of treatment (saline and LPS) and hormonal milieu (estradiol or oil capsule in ovariectomized mice or formestane and oil controls in ovary-intact mice) on lba1 immunoreactivity, cytokine protein levels, body weight, and estradiol levels using a two-way ANOVA. We corrected for multiple comparisons using Bonferroni corrections. All data in experimental 1 were normally distributed except for the $\mathrm{VMH}$ mean cell body area, the $\mathrm{VMH}$ total outgrowth, the VMH total branches, and the IL-1 $\alpha 24 \mathrm{~h}$. All data in experiment 2 were normally distributed except for $\mathrm{VMH}$ number of microglia, the total cell body area, the mean cell body area, IL-10 $6 \mathrm{~h}, \mathrm{IL}-1 \alpha 24 \mathrm{~h}, \mathrm{IL}-1 \beta 24 \mathrm{~h}$, IL$1024 \mathrm{~h}, \mathrm{TNF}-\alpha 24 \mathrm{~h}$, the changes in body weight at 6 and $24 \mathrm{~h}$, and the change in temperature. The statistical tests and observed powers were conducted using GraphPad Prism. Effect sizes estimates were calculated using $\eta^{2}$ for the ANOVAs (Levine and Hullett, 2002). Each comparison is indicated using superscript letters and numbers are listed in Tables 1, 2.

\section{Experiment 1: does estradiol influence the microglial, cytokine, and physiological response to LPS?}

A total of $128 \mathrm{C} 57 \mathrm{BI} / 6$ female mice were shipped on P21. Mice were ovariectomized and received a SILASTIC capsule implant on P35. Mice received an intraperitoneal 
Table 2: Experiment 2 statistical analysis

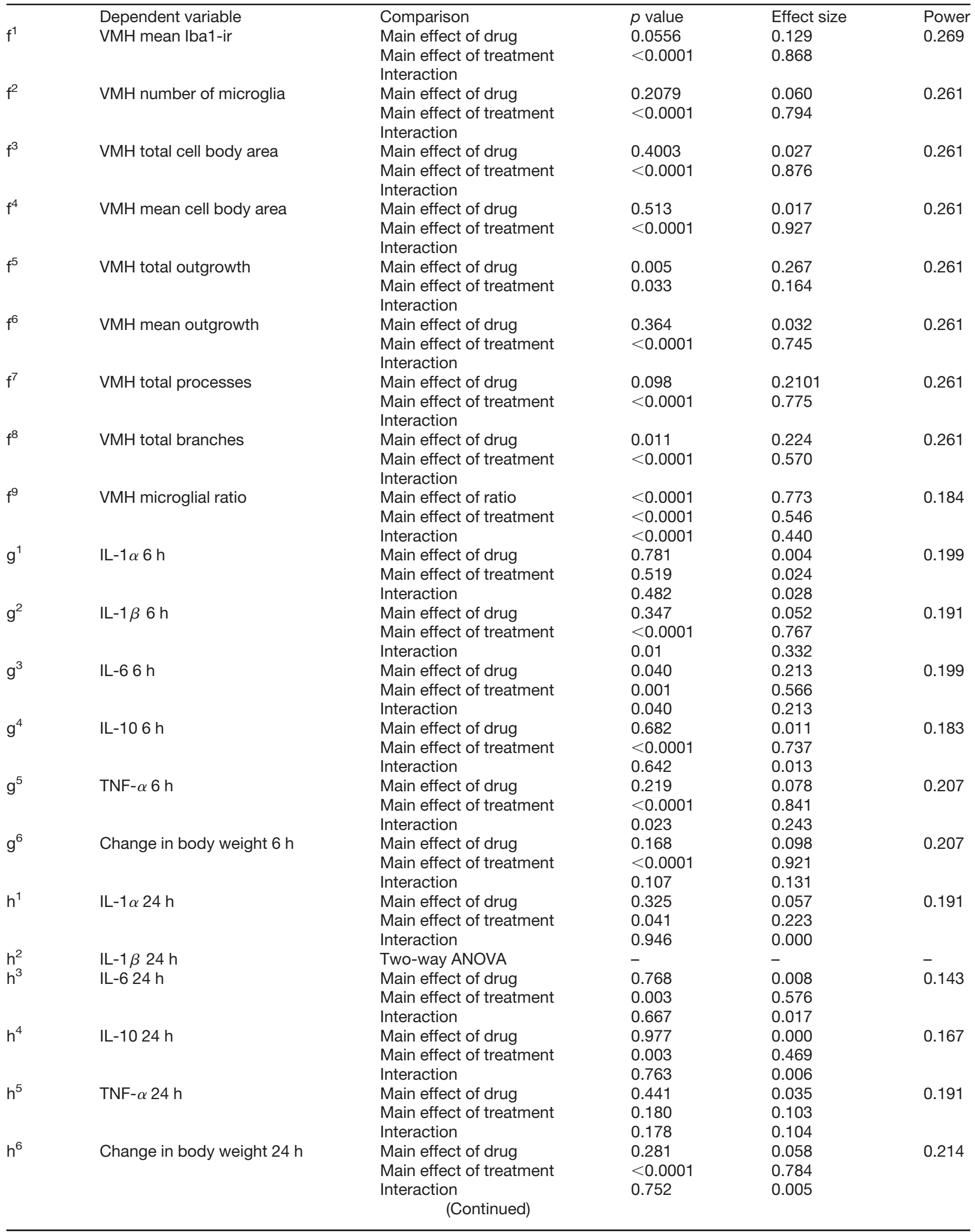


Table 2: Continued

\begin{tabular}{lllll}
\hline & Dependent variable & Comparison & $p$ value & Effect size \\
$\mathrm{i}^{1}$ & Change in temperature & Main effect of time & $<0.0001$ & 0.098 \\
& & Main effect of treatment & $<0.0001$ & 0.046 \\
$\mathrm{i}^{2}$ & Change in locomotion & Interaction & 0.145 & 0.113 \\
& & Main effect of time & $<0.0001$ & 0.150 \\
& Main effect of treatment & $<0.0001$ & 0.162 \\
& Interaction & 0.206 & 0.106 \\
\hline
\end{tabular}

Experiment 2. The effect of formestane on the microglial, cytokine, and physiological response to LPS

injection of LPS or sterile saline vehicle on P42 (Fig. 1A). Thirty-two mice were euthanized $24 \mathrm{~h}$ following saline or LPS administration on P43, and brains were removed immediately and placed into 4\% paraformaldehyde until processed for microglial analysis. Ninety-six mice were euthanized, decapitated, and trunk blood was collected either at $6 \mathrm{~h}$ postinjection (48 mice on P42) or $24 \mathrm{~h}$ postinjection (48 mice on P43) for cytokine analyses and physiological responses.

\section{Experiment 2: does formestane attenuate the microglial, cytokine, and physiological response to LPS?}

A total of $128 \mathrm{C} 57 \mathrm{BI} / 6$ female mice were shipped on P21. Mice received a daily injection of formestane or sesame oil for seven consecutive days from P35 to P42 (Fig. $1 B)$. Mice received an intraperitoneal injection of LPS or sterile saline vehicle on P42. Twenty-four hours following saline or LPS administration (on P43), 32 mice were euthanized and brains were removed immediately and placed into $4 \%$ paraformaldehyde until processed for microglial analysis. Ninety-six mice were euthanized, decapitated, and trunk blood was collected either at $6 \mathrm{~h}$ postinjection (48 mice on $\mathrm{P} 42$ ) or $24 \mathrm{~h}$ postinjection (48 mice on P43) for cytokine analyses and physiological responses.

\section{Results}

\section{Experiment 1}

Estradiol increases basal microglial Iba1 immunoreactivity in the $\mathrm{VMH}$

Estradiol increased basal microglial Iba1 immunoractivity $^{\mathrm{a} 1}$ in mice treated with saline control. This increase in microglial lba1 immunoreactivity is not due to differences in the total number of microglia ${ }^{\mathrm{a} 2}$ or differences in microglial cell body size ${ }^{\mathrm{a} 3, \mathrm{a} 4}$ (Fig. $2 C-E$ ). Overall, these results suggest that the estradiol-driven increase in the microglial lba1 immunoreactivity might enhance immune activation in the $\mathrm{VMH}$. As expected, microglia underwent robust changes in morphology following LPS treatment regardless of the hormone environment (Fig. 2). After LPS, there was an increase in microglia cell numbers ${ }^{\mathrm{a} 2}$ (Fig. $2 \mathrm{C}$ ), increased soma size $\mathrm{a}^{\mathrm{a}, \mathrm{a} 4}$ (Fig. 2D,E), and a decrease in their overall outgrowth ${ }^{\mathrm{a} 5, \mathrm{a} 6}$ (Fig. $\left.2 F, G\right)$, which was mainly driven by a decrease in microglial branches ${ }^{\mathrm{a} 7, \mathrm{a} 8}$ (Fig. 2/). The microglial ratio $^{\text {a9 }}$ analysis suggests that the cells undergoing these drastic morphologic changes are resident microglial cells within the $\mathrm{VMH}$, as there is a robust decrease in the number of basal microglia (ratio 0-0.99) and a concomitant increase in macrophage-like microglia (ratio $3.00+$; Fig. 2J).

LPS induces higher levels of plasma TNF- $\alpha$ in the presence of estradiol

Plasma levels of IL-1 $\alpha^{\mathrm{b} 1, \mathrm{c} 1}, \mathrm{IL}-1 \beta^{\mathrm{b} 2, \mathrm{c} 2}, \mathrm{IL}-6^{\mathrm{b} 3, \mathrm{c} 3}, \mathrm{IL}-$ $10^{\mathrm{b} 4, \mathrm{c} 4}$, and TNF- $\alpha^{\mathrm{b} 5, \mathrm{c} 5}$ were quantified at 6 and $24 \mathrm{~h}$ post-LPS administration. LPS caused a stronger induction of TNF- $\alpha$ and IL-10 in the presence of estradiol $6 \mathrm{~h}$ following LPS injection (Fig. 3G,l). IL-1 $\alpha$ levels were similar between ovariectomized mice that received saline or LPS 6 h postinjection (Fig. 3A) but LPS administration caused a nearly three-fold decrease in IL- $1 \alpha$ levels in ovariectomized, oil-controls $24 \mathrm{~h}$ following LPS administration (Fig. 3B). While LPS increased IL-6 levels in ovariectomized oil-controls and estradiol-treated mice 6 and $24 \mathrm{~h}$ post-LPS administration, the effect of LPS on IL-6 levels $6 \mathrm{~h}$ following LPS administration to ovariectomized, estradiol-treated mice did not reach statistical significance (Fig. 3E,F). LPS caused a decrease in body weight $6 \mathrm{~h}^{\mathrm{b} 6}$ and $24 \mathrm{~h}^{\mathrm{c} 6}$ after administration, compared with saline-treated controls (Fig. $3 K, L)$. The body weight change confirms that the LPS treatment reduced food intake (Fig. $3 K, L)$. Finally, the estradiol levels ${ }^{\mathrm{d} 1}$ further confirmed the appropriate delivery and release of estradiol from the capsules (Fig. 3M).

\section{LPS causes hypothermia in the presence of estradiol}

LPS caused hypothermia only in the presence of estra$\mathrm{diol}^{\mathrm{e}}{ }^{1}$ (Fig. 4A). This temperature change is not attributable to changes in locomotor activity, because estradioltreated and oil-treated control mice showed a similar reduction in locomotion ${ }^{\mathrm{e}}$ following LPS administration

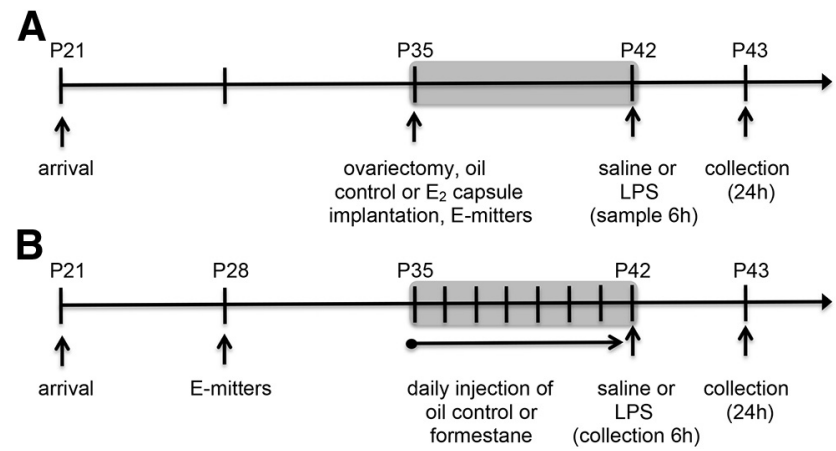

Figure 1. A, Experiment 1 timeline. B, Experiment 2 timeline. 
A

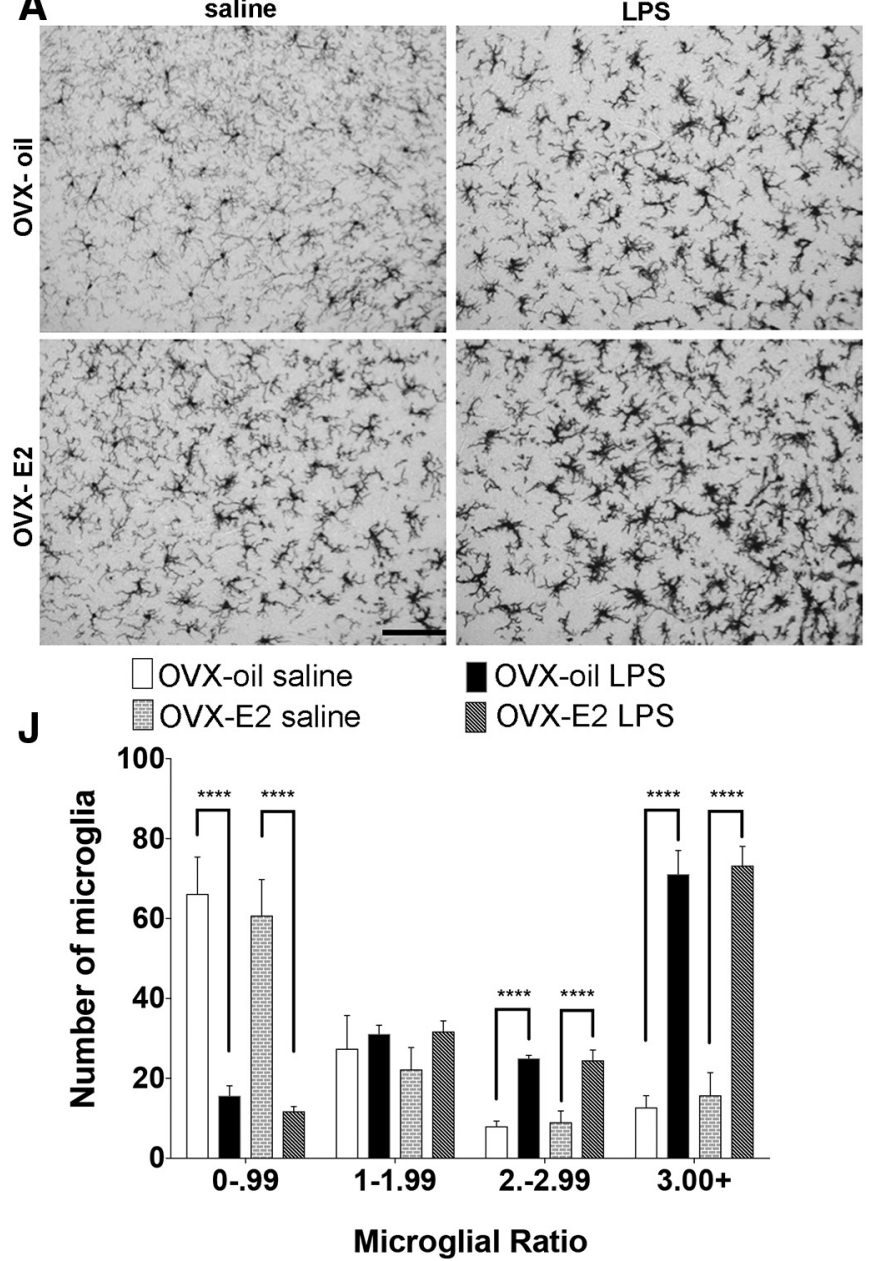

B
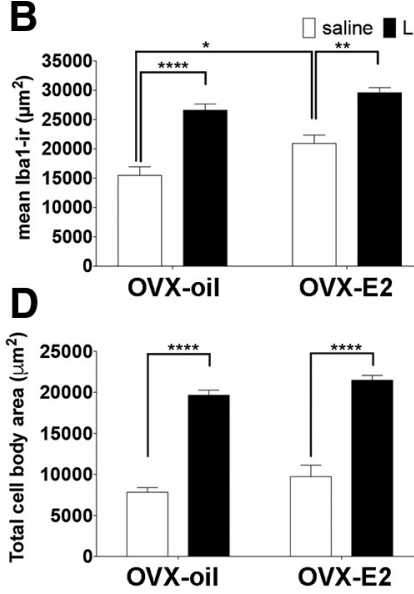

$F$

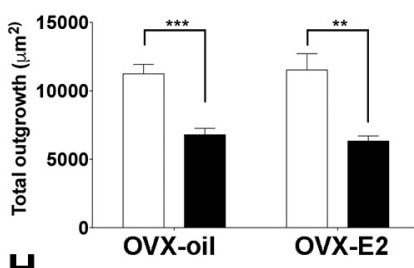

H

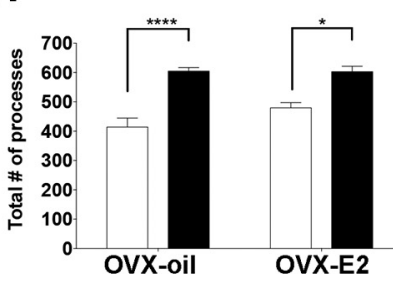

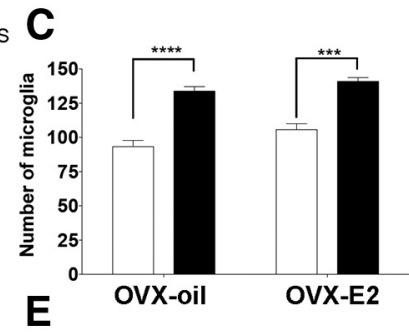

E

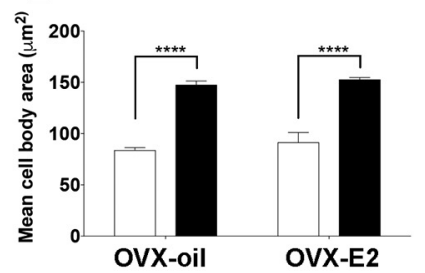

G
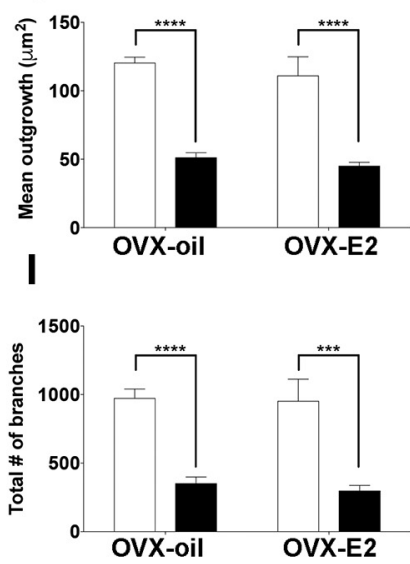

Figure 2. The effects of LPS on microglia in the VMH of ovariectomized (OVX) pubertal female mice that received an oil or estradiol $\left(E_{2}\right)$ capsule. $\boldsymbol{A}$, Representative photomicrographs of females treated with oil and saline, oil and LPS, $E_{2}$ and saline, $E_{2}$ and LPS. The effects of LPS on $(\boldsymbol{B})$ microglial lba1 immunoreactivity, $(\boldsymbol{C})$ number of microglia, $(\boldsymbol{D})$ total cell body area, $(\boldsymbol{E})$ mean cell body area, $(\boldsymbol{F})$ total outgrowth, $(\boldsymbol{G})$ mean outgrowth, $(\boldsymbol{H})$ total number of processes, and $(\boldsymbol{I})$ mean number of branches of microglia. $\boldsymbol{J}$, Microglial heterogeneity. All data are represented as mean \pm SEM with $* p<0.05, * * p<0.01, * * * p<0.001, * * * * p<0.0001$.

(Fig. 4A,B). Additionally, estradiol-treated and oil-treated controls returned to baseline locomotor activity at a similar time point (Fig. 4B).

\section{Experiment 2}

Formestane decreases basal microglial branching complexity in the $\mathrm{VMH}$

The aromatase inhibitor, formestane, prevents the synthesis of estradiol. Ovary-intact mice treated with oil show higher levels of microglial lba1 immunoreactivity at basal levels compared with mice treated with formestane ${ }^{\mathrm{f} 1}$ (Fig. $5 B$ ). The effect of formestane seems to be mediated via effects on microglial outgrowth ${ }^{f 5, f 6}$ (Fig. $5 F, l$ ) but not by the number of microglia ${ }^{\mathrm{e} 2}$ (Fig. $5 \mathrm{C}$ ) or by the cell body size $^{\mathrm{f} 3, \mathrm{f4}}$ (Fig. 5D,E). Specifically, the administration of formestane reduces the complexity of microglial branching ${ }^{\text {f8 }}$ (Fig. 5/). As expected, microglia underwent robust changes in morphology following LPS treatment regardless of the hormone environment (Fig. 5). After LPS treatment, there was an increase in microglia cell numbers (Fig. $5 C$ ), increased soma size (Fig. $5 D, E$ ), and a decrease in their overall outgrowth (Fig. $5 F, G$ ), which was mainly driven by a decrease in microglial branches (Fig. 5/). The microglial ratio analysis ${ }^{f 9}$ suggests that the majority of microglia undergoing these morphologic changes are resident microglial cells within the $\mathrm{VMH}$, as there is a robust decrease in the number of basal microglia (ratio 0-0.99) and a concomitant increase in macrophage-like microglia (ratio 3.00+; Fig. 5J).

\section{Formestane attenuates the induction of plasma IL-6 and}

IL-1 $\beta$ following LPS

Plasma levels of IL-1 $\alpha^{\mathrm{g} 1, \mathrm{~h} 1}, \mathrm{IL}-1 \beta^{\mathrm{g} 2, \mathrm{~h} 2}, \mathrm{IL}-6^{\mathrm{g} 3, \mathrm{~h} 3}, \mathrm{IL}-$ $10^{94, \mathrm{~h} 4}$, and TNF- $\alpha^{95, \mathrm{~h} 5}$ were quantified at 6 and $24 \mathrm{~h}$ post-LPS administration. In ovary-intact oil controls, LPS causes a stronger induction of IL-1 $\beta$ and IL-6, while formestane attenuates it $6 \mathrm{~h}$ following LPS administration (Fig. 6C,E). Not surprisingly, LPS increased the levels of IL-10 and TNF- $\alpha$, but the hormone environment did not 

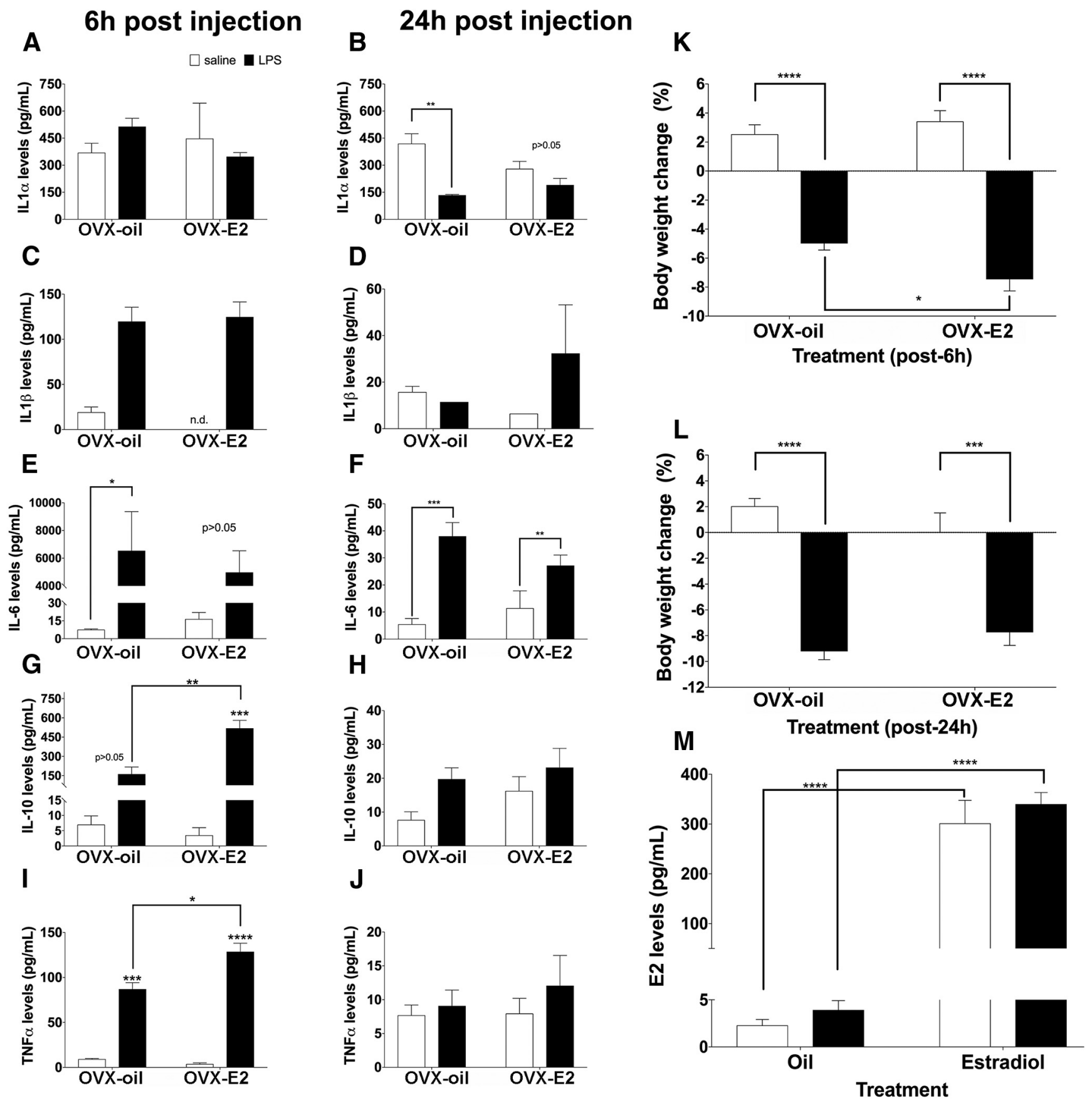

Figure 3. The effects of LPS on cytokine levels in ovariectomized (OVX) pubertal mice that received an oil or estradiol $\left(\mathrm{E}_{2}\right)$ capsule. Levels of $(\boldsymbol{A}, \boldsymbol{B}) \mathrm{IL}-1 \alpha,(\boldsymbol{C}, \boldsymbol{D}) \mathrm{IL}-1 \beta,(\boldsymbol{E}, \boldsymbol{F}) \mathrm{IL}-6,(\boldsymbol{G}, \boldsymbol{H}) \mathrm{IL}-10,(\boldsymbol{I}, \boldsymbol{J})$ TNF- $\alpha$ at $6 \mathrm{~h}(\boldsymbol{A}, \boldsymbol{C}, \boldsymbol{E}, \boldsymbol{G}, \boldsymbol{I})$, or $24 \mathrm{~h}(\boldsymbol{B}, \boldsymbol{D}, \boldsymbol{F}, \boldsymbol{H}, \boldsymbol{J})$ postinjection. The effects of LPS on body weight collected at $(\boldsymbol{K}) 6 \mathrm{~h}$ or $(\boldsymbol{L}) 24 \mathrm{~h}$ postinjection. $\boldsymbol{M}$, Plasma $\mathrm{E}_{2}$ levels of OVX female mice implanted with an oil or $\mathrm{E}_{2}$ capsule. All data are represented as mean $\pm \mathrm{SEM}$ with $* p<0.05, * * p<0.01, * * * p<0.001, * * * * p<0.0001$.

seem to modulate the levels of these cytokines (Fig. 6G). Overall, the levels of almost all of these cytokines had returned to baseline $24 \mathrm{~h}$ following LPS administration, suggesting that they are temporally regulated. Lastly, the body weight change ${ }^{g 6, h 6}$ suggests that the LPS treatment reduced food intake and/or induced changes in metabolism, both of which are consistent with sickness behavior (Fig. 6K,L). The estradiol levels for both groups were below the level of detection $(3 \mathrm{pg} / \mathrm{ml})$ for this experiment (data not shown).

\section{Formestane blocks LPS-induced hypothermia seen in} ovary-intact controls

LPS caused hypothermia only in the presence of estradioli (Fig. 7A). Only ovary-intact control mice showed a hypothermic response after LPS administration, while formestane blocked this induction (Fig. 7A). This temperature change cannot be attributed to changes in locomotor activity ${ }^{\mathrm{i} 2}$, because LPS-treated mice showed a similar reduction in locomotion following LPS administration regardless of whether the mice were able to synthesize estradiol (Fig. 7B). 


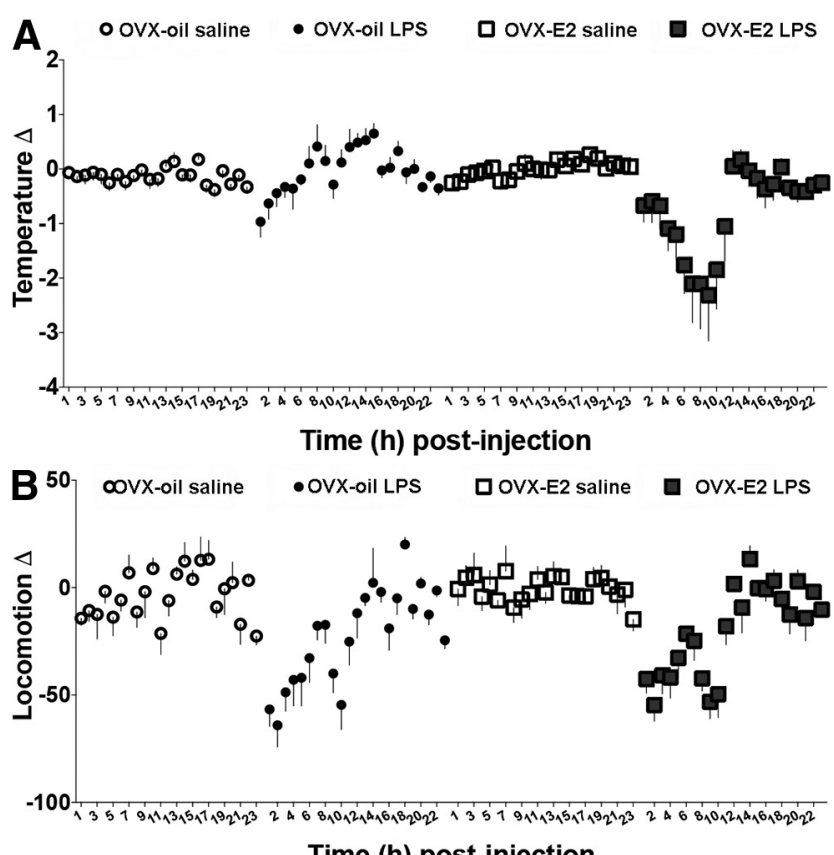

Time (h) post-injection

Figure 4. The effects of LPS administration on $(\boldsymbol{A})$ temperature and $(\boldsymbol{B})$ locomotion in ovariectomized (OVX) pubertal females that received an oil or estradiol $\left(E_{2}\right)$ capsule (mean \pm SEM).

\section{Discussion}

Previous research has demonstrated that female mice are vulnerable to LPS during the sensitive period of pubertal development. First, LPS exposure during the peripubertal period, but not in adulthood, alters multiple behaviors mediated by steroid hormones in adulthood (Laroche et al., 2009a,b; Ismail et al., 2011; Olesen et al., 2011). Second, the majority of microglia in the VMH of gonadally intact females are characterized by longer and thicker processes during the peripubertal period in contrast to the thinly ramified microglial phenotype observed in adulthood, and the microglia in the $\mathrm{VMH}$ of pubertal mice have a stronger response to LPS, compared with microglia of adult mice receiving the same treatment (Holder and Blaustein, 2017). Third, there is a reduction in the concentration of $\mathrm{ER} \alpha$ in the $\mathrm{VMH}$ if mice experience a shipping stressor during the peripubertal sensitive period (Ismail et al., 2011). Together, these data suggest that ovarian hormones may be important in conferring vulnerability to LPS during the peripubertal period. Here, we tested the hypothesis that estradiol confers vulnerability to LPS during the peripubertal period by modulating microglia. The present work indicates that estradiol increases microglial lba1 immunoreactivity and formestane treatment alters microglial branching complexity in the $\mathrm{VMH}$ and amplifies the LPS-induced immune response in female mice during pubertal development. The findings suggest that estradiol enhances immune activation during the peripubertal sensitive period and may confer vulnerability to LPS.

Estradiol elevates basal microglial Iba1 immunoreactivity and formestane administration reduces microglial branching in the $\mathrm{VMH}$. The microglial alterations may enhance the ability of microglia to respond more rapidly to perturbations in the microenvironment. Alternatively, it is possible that this type of microglia may act as the main driver of phagocytic activity during sensitive periods. While amoeboid microglia are typically associated with macrophage functions, new evidence shows that ramified microglia in the developing cerebellum contain phagocytic cups that are associated with cleaved caspase- 3 expression and cell nuclei fragmentation in a brain-region and time-dependent manner (Perez-Pouchoulen et al., 2015). Future studies should test whether these microglial ramifications contain phagocytic cups in estradiol treated mice. This may be one mechanism that could underlie the reduction in ER-positive cells in the VMH of mice exposed to a stressor during peripubertal development. In this study we did not investigate estrogen-receptor expression in microglia. It is possible that estrogen receptors are expressed only in a subset of microglia and we might be overlooking subtle nuances in microglial morphology that could inform microglial function. Future experiments should focus on studying ER-expressing microglia in the $\mathrm{VMH}$ to evaluate the effects of estradiol on microglial function in that population.

The increase in microglial lba1 immunoreactivity seen in the $\mathrm{VMH}$ of estradiol-treated mice is brain-region specific. Estradiol did not affect the microglial outgrowth in the AVPv or the ARC, areas which also express high levels of estrogen-receptors and undergo remodeling during the peripubertal period (data not shown). This region specificity may arise if the $\mathrm{VMH}$ is able to integrate signals from immune activity with the estradiol activity. For example, microinjections of prostaglandin $\mathrm{E}_{2}\left(\mathrm{PGE}_{2}\right)$ into the $\mathrm{VMH}$ causes a febrile response in rabbits (Morimoto et al., 1988). In addition, estradiol induces $P \mathrm{FE}_{2}$ synthesis and regulates microglial morphology and activity in the preoptic area in neonatal male pups (Amateau and McCarthy, 2004; Lenz et al., 2013). As LPS is able to stimulate the production of $\mathrm{PGE}_{2}$ (for review, see Ricciotti and FitzGerald, 2011), additional experiments should investigate whether a similar interaction between estradiol and $\mathrm{PGE}_{2}$ occurs in the $\mathrm{VMH}$ of pubertal female mice.

The notion that estradiol increases microglial lba1 immunoreactivity, which can be associated with an enhanced response to immune activation, during pubertal development is supported by the cytokine, thermoregulatory, and metabolic changes observed in mice. LPS induces higher levels of TNF- $\alpha$, hypothermia, and greater weight loss only in the presence of estradiol. Fever is a typical response to infection, but hypothermia is only induced in severe cases of inflammation (Romanovsky et al., 1996). Overall, these data show that these physiological changes are temporally regulated, and they suggest that estradiol is amplifying the LPS-induced immune response.

There are a couple of important caveats regarding the contributions of estradiol and other ovarian hormones to keep in mind when interpreting these data. First, these data indicate that presence of estradiol is required for the increased vulnerability to LPS during the peripubertal period; however, estradiol may not be the sole driver. In fact, 
A
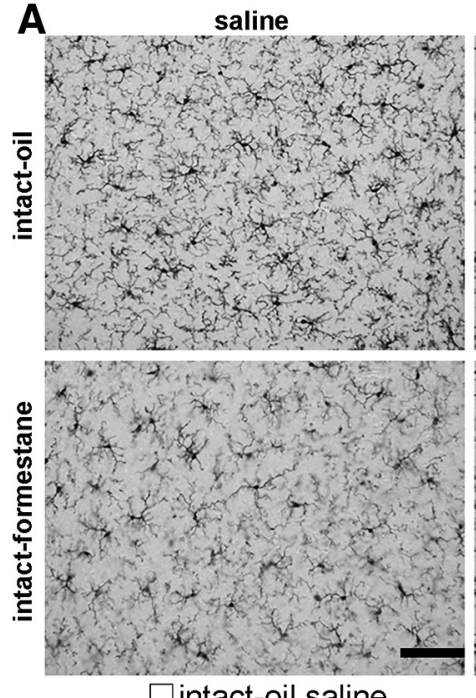

$\square$ intact-oil saline

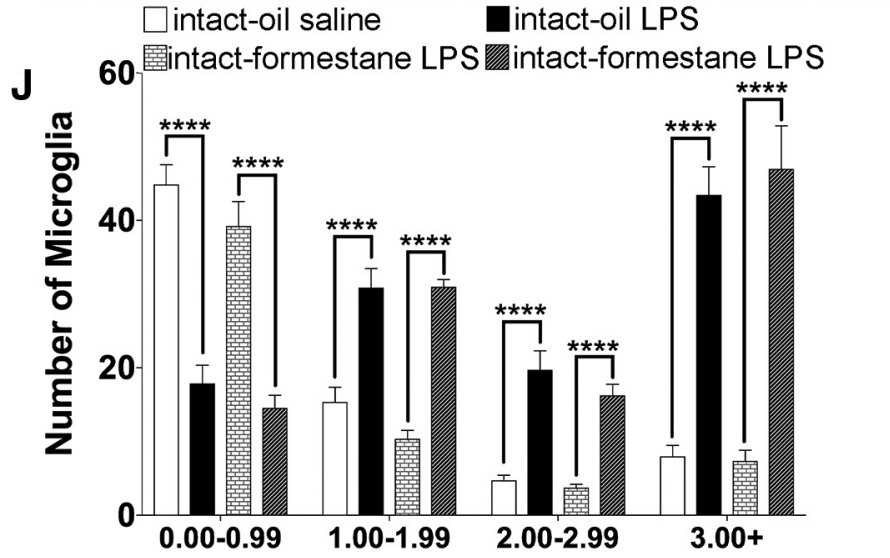

LPS
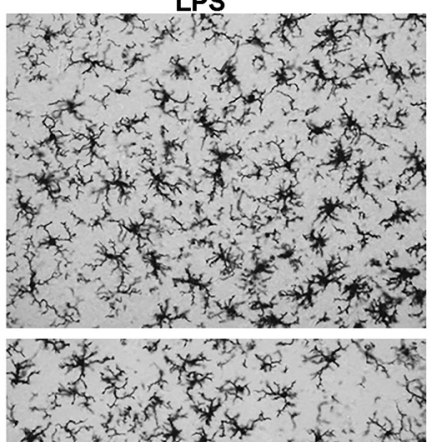

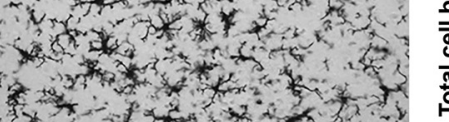

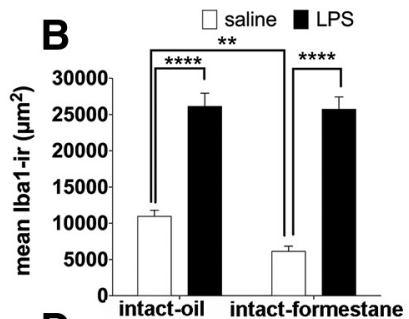
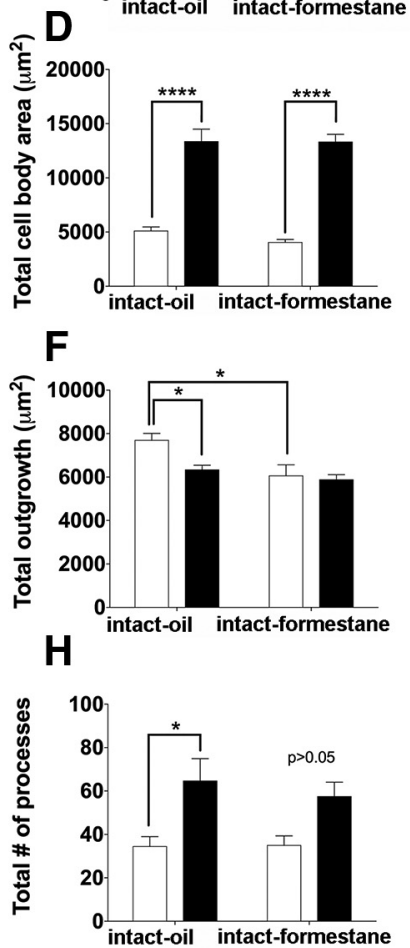
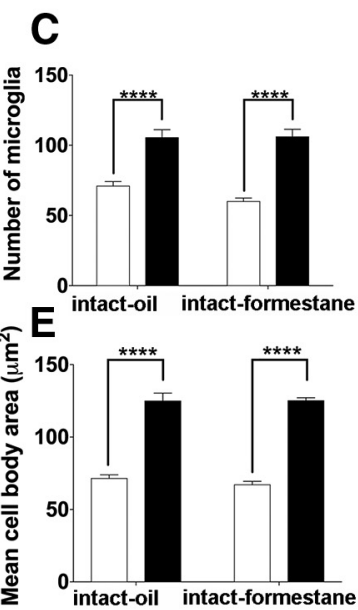

G
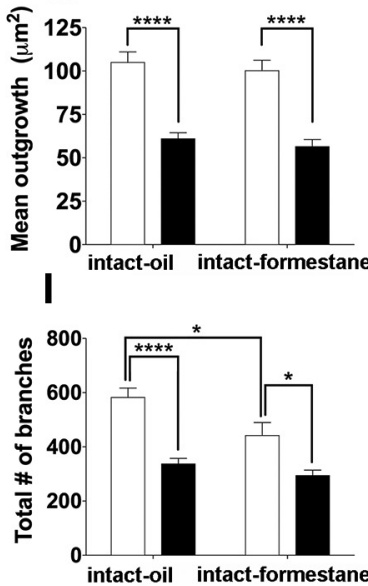

Ratio (cell body/outgrowth)

Figure 5. The effects of LPS on microglia in the VMH of intact pubertal female mice that received injections of either oil or the aromatase inhibitor formestane. A, Representative photomicrographs of females treated with oil and saline, oil and LPS, formestane and saline, formestane and LPS. The effects of LPS on $(\boldsymbol{B})$ microglial lba1 immunoreactivity, $(\boldsymbol{C})$ number of microglia, $(\boldsymbol{D})$ total cell body area, $(\boldsymbol{E})$ mean cell body area, $(\boldsymbol{F})$ total outgrowth, $(\boldsymbol{G})$ mean outgrowth, $(\boldsymbol{H})$ total number of processes, and $(\boldsymbol{I})$ mean number of branches of microglia. $\boldsymbol{J}$, Microglial heterogeneity. All data are represented as mean \pm SEM with $* p<0.05$, $* * p<0.01$, $* * * p<0.001, * * * * p<0.0001$.

one reason for the differences in microglial branching and cytokine expression between experiments 1 and 2 may be due to these other factors. Formestane, as an aromatase inhibitor, blocks the synthesis of estrogens, whereas the removal of the ovaries would also impact the estrogens and other ovarian hormones such as progestins. Therefore, adding back estradiol after removal of the ovaries is not the opposite of blocking synthesis of estrogens all over the body. The second relates to the estradiol levels. Although the route of administration of estradiol used in this study rescues the effects of ovariectomy on several markers of pubertal maturation (Clarkson et al., 2009), it is unknown whether the concentration of estradiol is within the physiological range for peripubertal mice. Therefore, we cannot exclude the possibility that the level of estradiol administered to peripubertal animals in experiment 1 was supraphysiological. Our estradiol assay was insufficiently sensitive to measure the blood levels of estradiol in the ovary-intact mice in experiment 2. The low levels of estradiol may be due to the developmental status of the mice, as the levels of estradiol increase over the course of pubertal development (deCatanzaro et al., 2004). The dose and injection procedure of formestane reduces brain levels of estradiol and estradiol-dependent changes in dendritic morphology in perinatal rats (Amateau et al., 2004; Dean et al., 2012); thus, the possibility remains that future experiments would show differences in the brain levels of estradiol in pubertal female mice treated formestane. However, the efficacy of formestane administration on the inhibition of aromatization and estradiol levels in the current study could not be determined.

Another caveat to keep in mind when interpreting these microglia data are that they reflect the interaction between the hormone environment and an immune challenge at a 

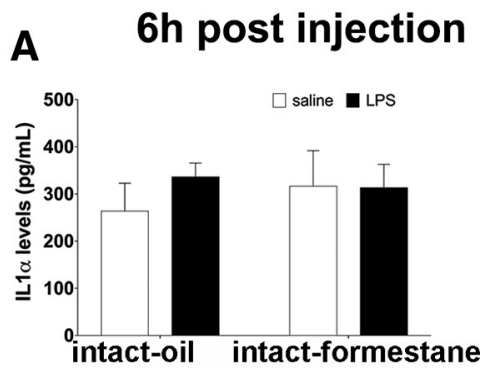

C

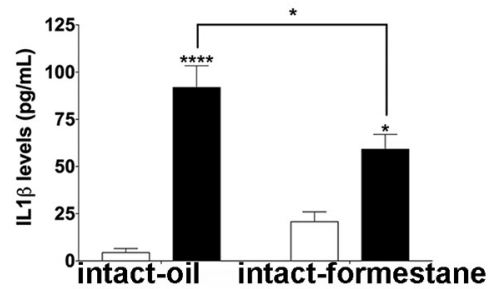

$\mathbf{E}$

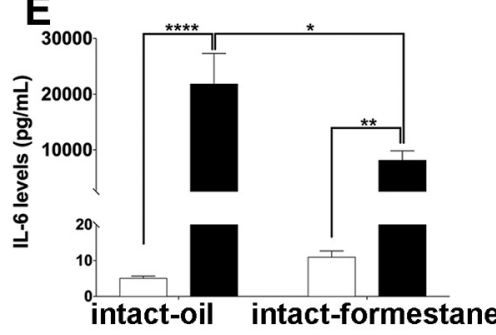

G

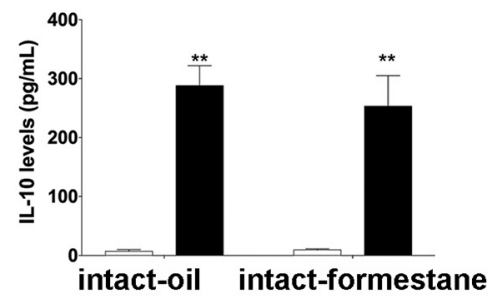

I

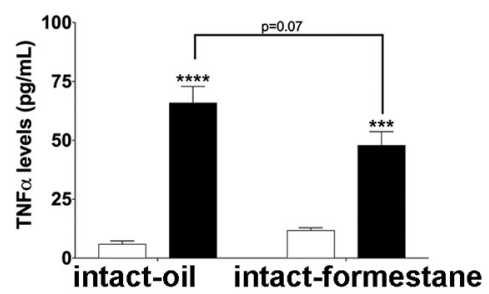

B 24h post injection
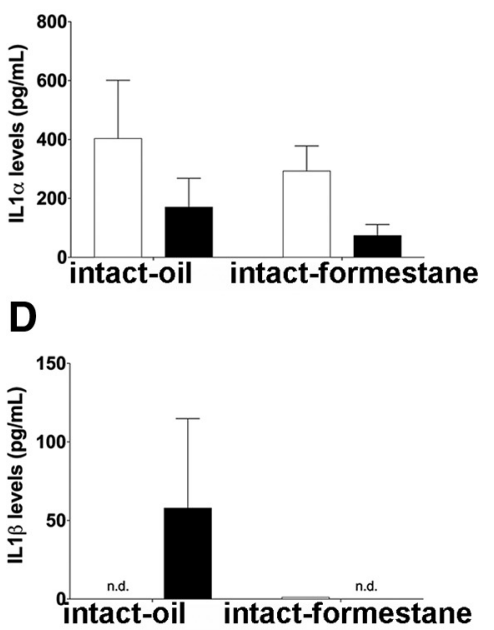

F
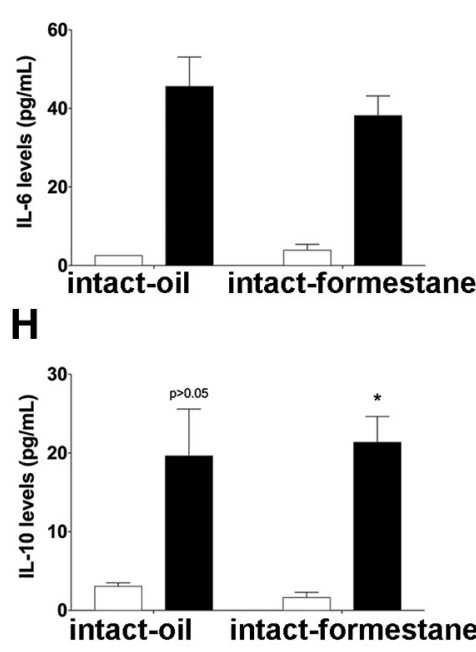

J

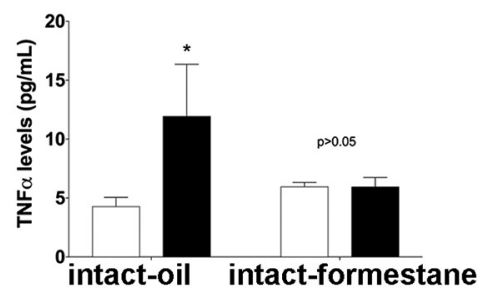

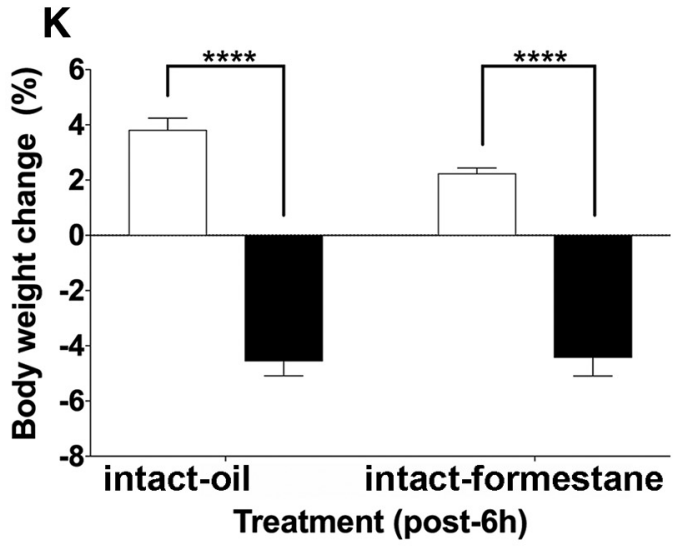

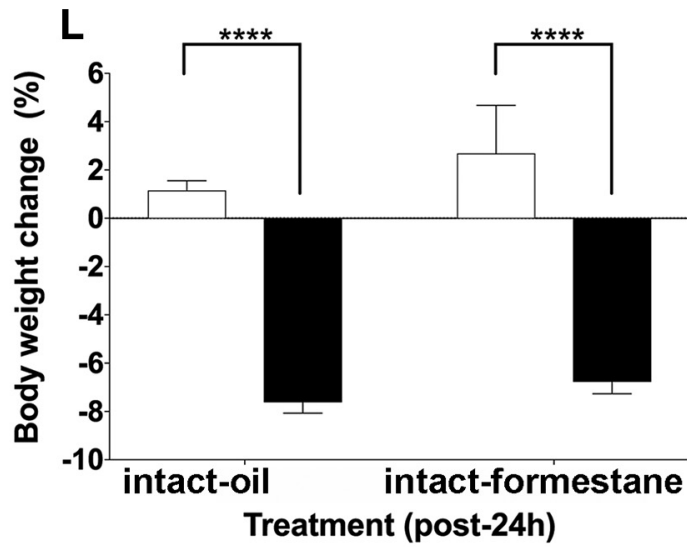

Figure 6. The effects of LPS on cytokine levels in intact pubertal mice that received injections of either oil or the aromatase inhibitor formestane. Levels of $(\boldsymbol{A}, \boldsymbol{B}) \mathrm{IL}-1 \alpha,(\boldsymbol{C}, \boldsymbol{D}) \mathrm{IL}-1 \beta,(\boldsymbol{E}, \boldsymbol{F}) \mathrm{IL}-6,(\boldsymbol{G}, \boldsymbol{H}) \mathrm{IL}-10,(\boldsymbol{I}, \boldsymbol{J})$ TNF- $\alpha$ at $6 \mathrm{~h}(\boldsymbol{A}, \boldsymbol{C}, \boldsymbol{E}, \boldsymbol{G}, \boldsymbol{I})$ or $24 \mathrm{~h}(\boldsymbol{B}, \boldsymbol{D}, \boldsymbol{F}, \boldsymbol{H}, \boldsymbol{J})$ postinjection. The effects of LPS on body weight collected at $(\boldsymbol{K}) 6 \mathrm{~h}$ or $(\boldsymbol{L}) 24 \mathrm{~h}$ postinjection. All data are represented as mean \pm SEM with $* p<0.05, * * p<0.01, * * * p<0.001, * * * * p<0.0001$.

single time point (24 h postinjection). Our behavioral, physiological, cytokine, and metabolic data showed dynamic changes in the immune response within the first 24 $\mathrm{h}$ after LPS administration. It is possible that the effect of estradiol on microglial morphology is also temporally regulated. In addition, the cytokine analysis was performed using plasma samples, so the cytokine levels in the hypothalamus are unknown. Therefore, future studies should be conducted to determine the cytokine levels in hypothalamic homogenates. Lastly, it is important to investigate whether these manipulations that impact the microglia also prevent the altered hormone-responsive behaviors in adulthood.

While both, pubertal males and females, are sensitive to shipping from the breeder facility as indicated by reduction in the sexual behaviors in adulthood, females show a more robust response (Laroche et al., 2009b). It is unknown whether this is because there is a sex differences 

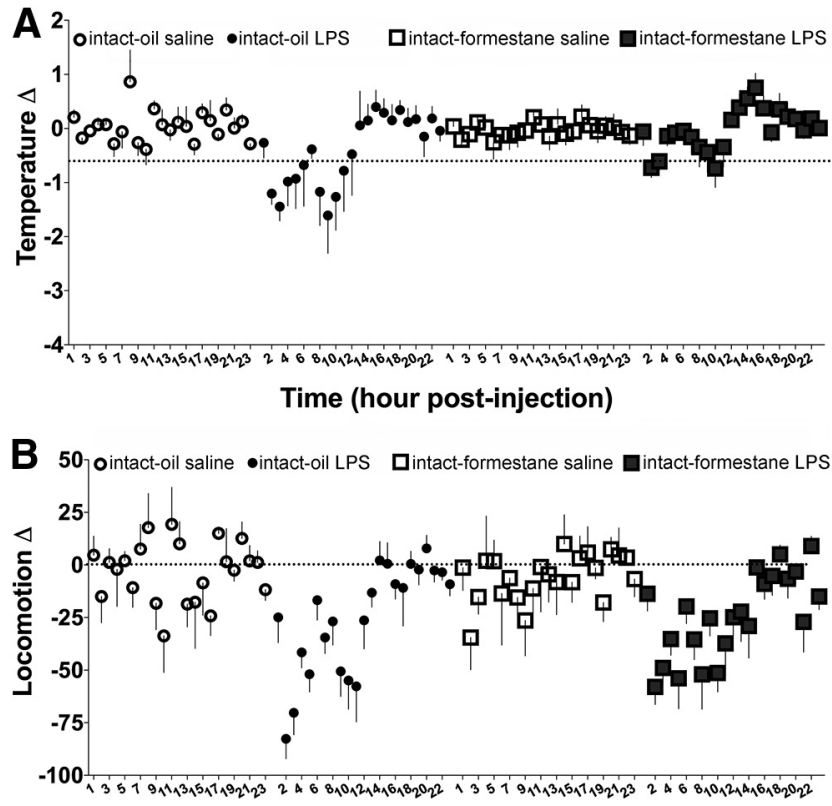

Time (hour post-injection)

Figure 7. The effects of LPS administration on $(\boldsymbol{A})$ temperature and $(\boldsymbol{B})$ locomotion in intact pubertal females that received injections of either oil or the aromatase inhibitor formestane (mean \pm SEM)

in the vulnerability or whether the timing chosen for the stressor is not ideal in male mice. The pattern of events that lead to sexual differentiation differs greatly between the sexes, so there may not be an objective way to determine the most comparable time to expose pubertal males to these stressors that would provide meaningful sex difference information. Therefore, although this work supports a robust effect of certain stressors during the peripubertal period in females, it does not directly address sex as a biological variable.

The goal of the present work was to examine the potential cellular underpinnings of the vulnerability of female mice to LPS administered in the peripubertal period. The present work suggests that estradiol may be a key factor in conferring vulnerability to LPS during the peripubertal sensitive period. While not tested directly, the increase in estradiol-driven microglial Iba1 immunoreactivity may suggest that microglia in the $\mathrm{VMH}$ are more active during the peripubertal period. Regardless, estradiol seems to amplify the LPS-induced responses in female mice during pubertal development at the microglial, cytokine, and thermoregulatory levels. It is possible that there is an enhanced interaction between the endocrine and immune systems as part of typical pubertal development. However, exposure to an immune stressor like LPS intensifies the immune signaling pathways to a threshold that may have detrimental effects. Although the present experiments do not directly address the issue of the effects of peripubertal immune challenge or shipping stress on later behavioral response to estradiol, they suggest that estradiol enhances the effect of LPS during the pubertal sensitive period.

\section{References}

Amateau SK, McCarthy MM (2004) Induction of PGE2 by estradiol mediates developmental masculinization of sex behavior. Nat Neurosci 7:643-650.

Amateau SK, Alt JJ, Stamps CL, McCarthy MM (2004) Brain estradiol content in newborn rats: sex differences, regional heterogeneity, and possible de novo synthesis by the female telencephalon. Endocrinology 145:2906-2917.

Avital A, Richter-Levin G (2005) Exposure to juvenile stress exacerbates the behavioural consequences of exposure to stress in the adult rat. Int J Neuropsychopharmacol 8:163-173.

Bakker J, Honda S, Harada N, Balthazart J (2003) The aromatase knockout (ArKO) mouse provides new evidence that estrogens are required for the development of the female brain. Ann NY Acad Sci 1007:251-262.

Beynon SB, Walker FR (2012) Microglial activation in the injured and healthy brain: what are we really talking about? Practical and theoretical issues associated with the measurement of changes in microglial morphology. Neuroscience 225:162-171.

Bilbo SD, Schwarz JM (2009) Early-life programming of later-life brain and behavior: a critical role for the immune system. Front Behav Neurosci 3:14.

Bilbo SD, Schwarz JM (2012) The immune system and developmental programming of brain and behavior. Front Neuroendocrinol 33:267-286.

Bilbo SD, Biedenkapp JC, Der-Avakian A, Watkins LR, Rudy JW, Maier SF (2005) Neonatal infection-induced memory impairment after lipopolysaccharide in adulthood is prevented via caspase-1 inhibition. J Neurosci 25:8000-8009.

Bilbo SD, Barrientos RM, Eads AS, Northcutt A, Watkins LR, Rudy JW, Maier SF (2008) Early-life infection leads to altered BDNF and IL-1beta mRNA expression in rat hippocampus following learning in adulthood. Brain Behav Immun 22:451-455.

Blaustein JD, Ismail N (2013) Enduring influence of pubertal stressors on behavioral response to hormones in female mice. Horm Behav 64:390-398.

Brock O, Baum MJ, Bakker J (2011) The development of female sexual behavior requires prepubertal estradiol. J Neurosci 31:55745578.

Brown CM, Mulcahey TA, Filipek NC, Wise PM (2010) Production of proinflammatory cytokines and chemokines during neuroinflammation: novel roles for estrogen receptors alpha and beta. Endocrinology 151:4916-4925.

Clarkson J, Boon WC, Simpson ER, Herbison AE (2009) Postnatal development of an estradiol-kisspeptin positive feedback mechanism implicated in puberty onset. Endocrinology 150:3214-3220.

Dantzer R (2001) Cytokine-induced sickness behavior: mechanisms and implications. Ann NY Acad Sci 933:222-234.

Dean SL, Wright CL, Hoffman JF, Wang M, Alger BE, McCarthy MM (2012) Prostaglandin Ell stimulates estradiol synthesis in the cerebellum postnatally with associated effects on Purkinje neuron dendritic arbor and electrophysiological properties. Endocrinology 153:5415-5427.

deCatanzaro D, Muir C, Beaton EA, Jetha M (2004) Non-invasive repeated measurement of urinary progesterone, 17beta-estradiol, and testosterone in developing, cycling, pregnant, and postpartum female mice. Steroids 69:687-696.

Franklin KBJ, Paxinos G (1997) The mouse brain in stereotaxic coordinates. San Diego: Academic Press.

Gertig U, Hanisch UK (2014) Microglial diversity by responses and responders. Front Cell Neurosci 8:101.

Green MR, McCormick CM (2013) Effects of stressors in adolescence on learning and memory in rodent models. Horm Behav 64:364-379.

Hanisch UK (2013) Functional diversity of microglia - how heterogeneous are they to begin with? Front Cell Neurosci 7:65.

Holder MK, Blaustein JD (2017) Developmental time course and effects of immunostressors that alter hormone-responsive behavior 
on microglia in the peripubertal and adult female mouse brain. PLoS One 12:e0171381.

Hong S, Stevens B (2016) Microglia: phagocytosing to clear, sculpt, and eliminate. Dev Cell 38:126-128.

Hovens IB, van Leeuwen BL, Nyakas C, Heineman E, van der Zee EA, Schoemaker RG (2015) Postoperative cognitive dysfunction and microglial activation in associated brain regions in old rats. Neurobiol Learn Mem 118:74-79.

Ismail N, Garas P, Blaustein JD (2011) Long-term effects of pubertal stressors on female sexual receptivity and estrogen receptor- $\alpha$ expression in CD-1 female mice. Horm Behav 59:565-571.

Knox AM, Li XF, Kinsey-Jones JS, Wilkinson ES, Wu XQ, Cheng YS, Milligan SR, Lightman SL, O'Byrne KT (2009) Neonatal lipopolysaccharide exposure delays puberty and alters hypothalamic Kiss1 and Kiss1r mRNA expression in the female rat. $J$ Neuroendocrinol 21:683-689.

Knudsen El (2004) Sensitive periods in the development of the brain and behavior. J Cogn Neurosci 16:1412-1425.

Laroche J, Gasbarro L, Herman JP, Blaustein JD (2009a) Enduring influences of peripubertal/adolescent stressors on behavioral response to estradiol and progesterone in adult female mice. Endocrinology 150:3717-3725.

Laroche J, Gasbarro L, Herman JP, Blaustein JD (2009b) Reduced behavioral response to gonadal hormones in mice shipped during the peripubertal/adolescent period. Endocrinology 150:23512358.

Lenz KM, Nugent BM, Haliyur R, McCarthy MM (2013) Microglia are essential to masculinization of brain and behavior. J Neurosci 33:2761-2772.

Levine TR, Hullett CR (2002) Eta squared, partial eta squared, and misreporting of effect size in communication research. Hum Commun Res 28:612-625.

McNamara KM, Harwood DT, Simanainen U, Walters KA, Jimenez M, Handelsman DJ (2010) Measurement of sex steroids in murine blood and reproductive tissues by liquid chromatography-tandem mass spectrometry. J Steroid Biochem Mol Biol 121:611-618.

Mor G, Nilsen J, Horvath T, Bechmann I, Brown S, Garcia-Segura LM, Naftolin F (1999) Estrogen and microglia: a regulatory system that affects the brain. J Neurobiol 40:484-496.

Morimoto A, Murakami N, Nakamori T, Watanabe T (1988) Ventromedial hypothalamus is highly sensitive to prostaglandin Ell for producing fever in rabbits. J Physiol 397:259-268.
Olesen KM, Ismail N, Merchasin ED, Blaustein JD (2011) Long-term alteration of anxiolytic effects of ovarian hormones in female mice by a peripubertal immune challenge. Horm Behav 60:318-326.

Paolicelli RC, Gross CT (2011) Microglia in development: linking brain wiring to brain environment. Neuron Glia Biol 7:77-83.

Perez-Pouchoulen M, VanRyzin JW, McCarthy MM (2015) Morphological and phagocytic profile of microglia in the developing rat cerebellum. eNeuro 2:ENEURO.0036-15.2015.

Ricciotti E, FitzGerald GA (2011) Prostaglandins and inflammation. Arterioscler Thromb Vasc Biol 31:986-1000.

Romanovsky AA, Shido O, Sakurada S, Sugimoto N, Nagasaka T (1996) Endotoxin shock: thermoregulatory mechanisms. Am J Physiol 270:R693-R703.

Schafer DP, Lehrman EK, Kautzman AG, Koyama R, Mardinly AR, Yamasaki R, Ransohoff RM, Greenberg ME, Barres BA, Stevens B (2012) Microglia sculpt postnatal neural circuits in an activity and complement-dependent manner. Neuron 74:691-705.

Schwarz JM, Sholar PW, Bilbo SD (2012) Sex differences in microglial colonization of the developing rat brain. J Neurochem 120:948-963.

Sierra A, Gottfried-Blackmore A, Milner TA, McEwen BS, Bulloch K (2008) Steroid hormone receptor expression and function in microglia. Glia 56:659-674.

Simpson ER, Dowsett M (2002) Aromatase and its inhibitors: significance for breast cancer therapy. Recent Prog Horm Res 57:317338.

Stevens B, Allen NJ, Vazquez LE, Howell GR, Christopherson KS, Nouri N, Micheva KD, Mehalow AK, Huberman AD, Stafford B, Sher A, Litke AM, Lambris JD, Smith SJ, John SW, Barres BA (2007) The classical complement cascade mediates CNS synapse elimination. Cell 131:1164-1178.

Tremblay ME, Lowery RL, Majewska AK (2010) Microglial interactions with synapses are modulated by visual experience. PLoS Biol 8:e1000527.

Vegeto E, Bonincontro C, Pollio G, Sala A, Viappiani S, Nardi F, Brusadelli A, Viviani B, Ciana P, Maggi A (2001) Estrogen prevents the lipopolysaccharide-induced inflammatory response in microglia. J Neurosci 21:1809-1818.

Yue W, Brodie AM (1997) Mechanisms of the actions of aromatase inhibitors 4-hydroxyandrostenedione, fadrozole, and aminoglutethimide on aromatase in JEG-3 cell culture. J Steroid Biochem Mol Biol 63:317-328. 